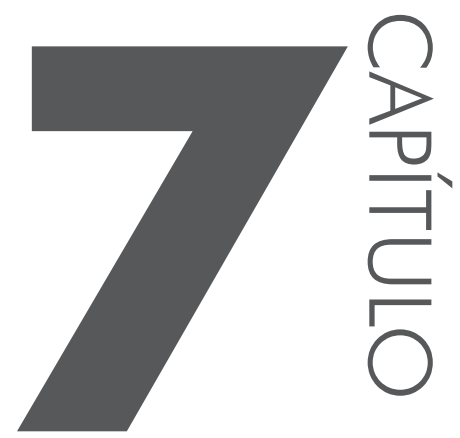

\title{
Mapas, cartografias e fronteiras
}

\section{Simoni Mendes de Paula e José Nilo Bezerra Diniz Doutorandos do Programa de Pós-Graduação em História/UFSC}

Desde o século XVIII, o reino de Portugal, por meio de seu secretário de Estado da Marinha e dos Domínios Ultramarinos, Dom Rodrigo de Sousa Coutinho, passou a empreender uma série de levantamentos cartográficos de suas possessões ultramarinas, no sentido de investigar e conhecer seus territórios - inclusive a África meridional - e como estes concorriam para o aumento da Real Fazenda. Dentre os planos de Sousa Coutinho reservados à África meridional, merece especial atenção seu desejo de unir as duas principais possessões portuguesas na costa índica e atlântica da África, a saber, Moçambique e Angola. O programa de Dom Rodrigo de Sousa Coutinho tinha origem nas ideias do diplomata português, Dom Luís da Cunha, que elaborara, juntamente com o geógrafo francês D'Anville, um plano de travessia continental. A concretização do plano traria três benefícios ao Império português a um só tempo: impediria o avanço dos colonos flamengos instalados no Cabo, pouparia os navios lusos da perigosa travessia marítima do Cabo da Boa Esperança e reorientaria o comércio de ouro e marfim que abundavam na hinterlândia para a costa atlântica.

Foi nesse contexto que se deram as primeiras produções cartográficas do que hoje compreende o território sul de Angola. Os primeiros mapas produzidos, no entanto, demonstram a falta de conhecimentos diretos da região em questão. O mapa abaixo, produzido por D'Anville em 1725, representa o que se sabia da região em meados do século XVIII. Nele, estão apontados os principais centros 
de poder africanos, seus caminhos e os postos portugueses, sobretudo espalhados pela costa. Do sul, as poucas marcações que se pode observar são algumas sinuosidades e marcos geográficos litorâneos, como Cabo Negro. Assim, os espaços incompletos no mapa cresciam à medida que seguia a sul e ao interior. A fronteira do território investigado pelos europeus é o rio Cunene, também denominado no mapa de "Grande rio".

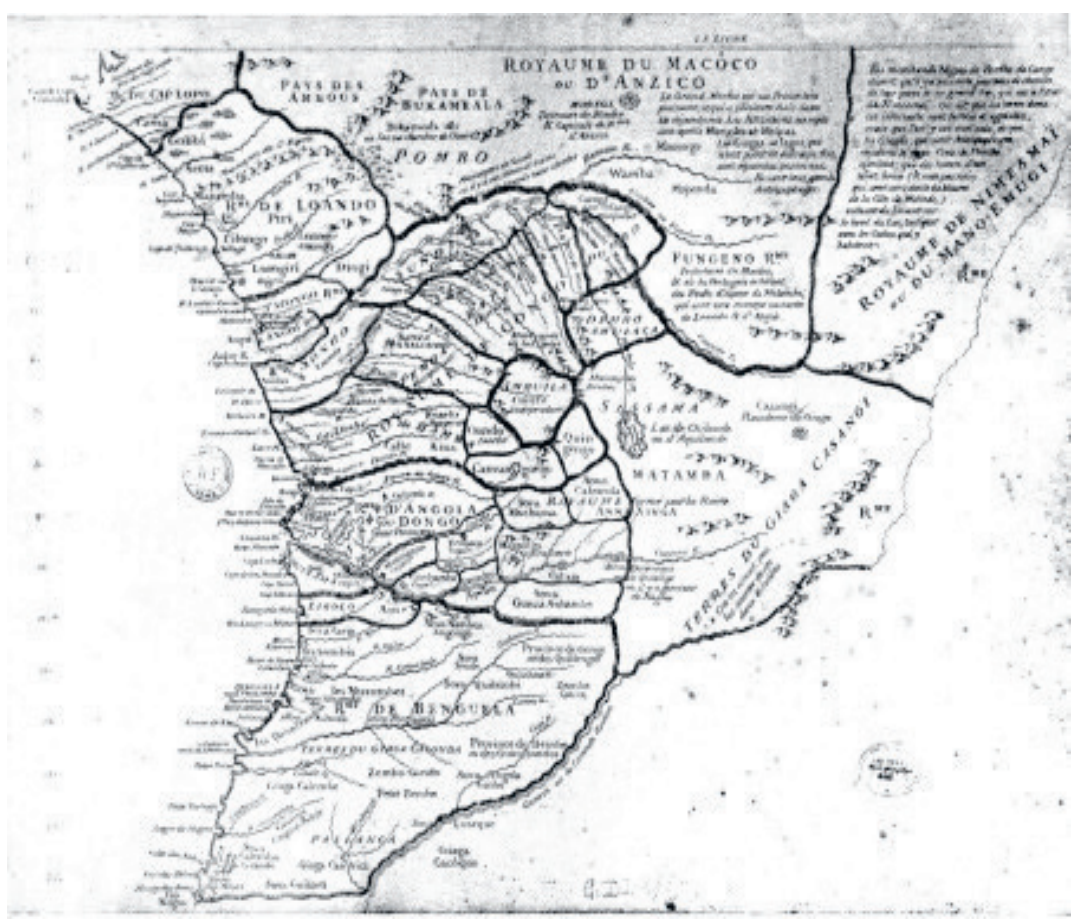

Figura 7.1 - Carta do Congo, Angola e Benguela de Bourguignon D'Anville, 1725. Fonte: In: MOTA, A. Teixeira da.D. Luís da Cunha e a Carta da África Meridional de Bourguignon D'Anville (1725). Coimbra: Instituto de Estudos Históricos, 1962. Separata da Revista Portuguesa de História.

O motivo da ausência de informações além-Cunene era a carência de relações descritivas de viajantes, missionários, comerciantes e outros exploradores pela região, o que era imprescindível para a geografia iluminista, que se pautava na compilação desses relatos. A despeito do desconhecimento, o território próximo ao rio Cunene era estratégico aos desígnios portugueses, pois se pensava que o leito desse rio seria a melhor forma de conectar as possessões portuguesas na costa atlântica e índica. Além disso, planejava-se traçar uma rota comercial ligando-o ao rio Cuanza, que corria paralelamente mais a norte.

Foi nesse sentido que, em 1785, o então governador-geral de Angola, Barão de Moçâmedes, destacou uma missão exploratória com o objetivo de demarcar a foz do rio Cunene e de investigar as possibilidades de penetrar no interior através dessa linha fluvial. De acordo com as instruções escritas pelo Barão de Moçâ- 
medes em 20 de maio de 1785, destinadas para a tropa expedicionária, fazia-se necessário seguir a corrente principal do rio, ignorando as ribeiras e riachos que corressem para norte, até que se encontrasse a foz do rio.

Em suas cartas, o Barão de Moçâmedes expõe a sua opinião acerca da pertinência dos caminhos fluviais. Comenta a inutilidade e até o dispêndio de construir e manter uma rede de fortes e feiras no interior da África, não havendo uma malha hídrica e ligação marítima que pudessem incrementar o comércio no sul de Angola. A expedição, chefiada pelo então capitão de granadeiros, António José da Costa, contou com a participação do naturalista luso-brasileiro Joaquim José da Silva e Pinheiro Furtado, mas não logrou a interiorização esperada e teve seus trabalhos concluídos em 1787.

O mapa a seguir foi produzido por Pinheiro Furtado em 1786, com base em suas anotações e observações durante as missões de 1785-1787, e talvez seja a primeira representação cartográfica do território Ovambo de que se tem notícia. Embora o espaço africano esteja representado a partir de instrumentos cognitivos europeus devedores de uma visão eurocêntrica, os mapas fornecem informações acerca da organização sócio-espacial dos poderes africanos. Nesse caso, o mapa de Pinheiro Furtado apresenta a distribuição dos Ovambo em um período anterior à organização dos reinos do Cuamato e Cuanhama. Além disso, circunscreve o território de habitação deles e aponta, por meio de uma legenda preconceituosa que diz "povos bárbaros de vida vagabunda e pastoral”, a principal atividade dos grupos do além-Cunene.

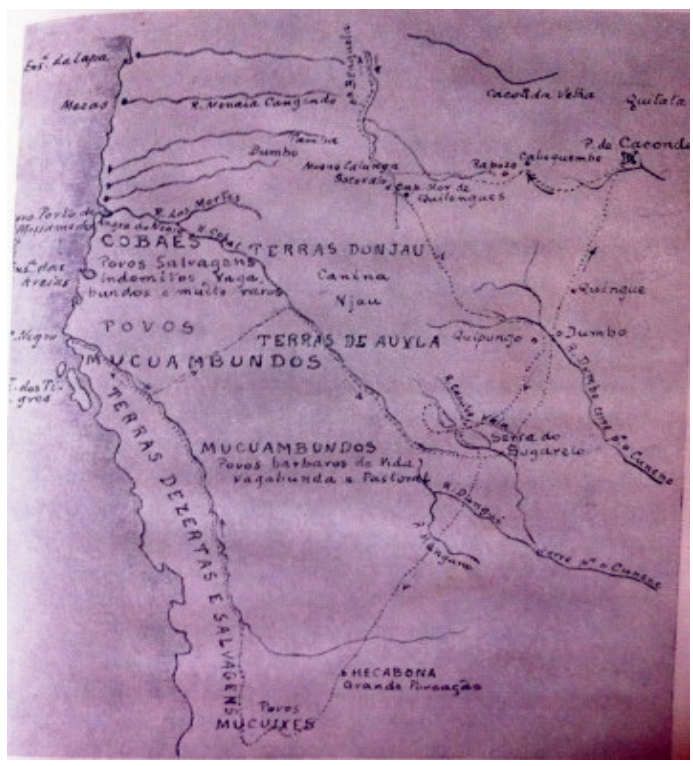

Figura 7.2 - Trecho da carta de Pinheiro Furtado, com o roteiro da expedição ao Cabo Negro, 1786. Fonte: In: DIAS, Gastão Sousa. Pioneiros de Angola: explorações portuguesas no sul de Angola (séculos XVII e XVIII). Lisboa: Agência Geral do Ultramar, 1937, p. 71. 
Quase um século depois dessas missões além da margem esquerda do rio Cunene, o processo de investigação e exploração do território seria bruscamente acelerado pela disputa geográfico-diplomática impulsionada pela chamada "Partilha da África”. Temendo pela perda de territórios por eles reivindicados, alguns setores da sociedade portuguesa adeptos do projeto colonial incentivaram a criação de expedições cartográficas aos territórios do interior da África austral e central. É nesse novo contexto que os militares Hermenegildo Capelo e Roberto Ivens são destacados pela Sociedade de Geografia de Lisboa para investigar a hinterlândia e realizar uma carta geral de Angola. O interesse dos geógrafos pelo sul de Angola focava nas vastas zonas desconhecidas entre os rios Cubango (Okavango) e Cunene e nas relações deste com o curso do rio Coróca. Durante a viagem, Capelo e Ivens elaboraram importantes cartas geodésicas da região sul. Estas diferiam dos mapas do século XVIII pelo nível de detalhes e precisão, fruto da formulação pela observação in loco e não mais através de descrições textuais do espaço.

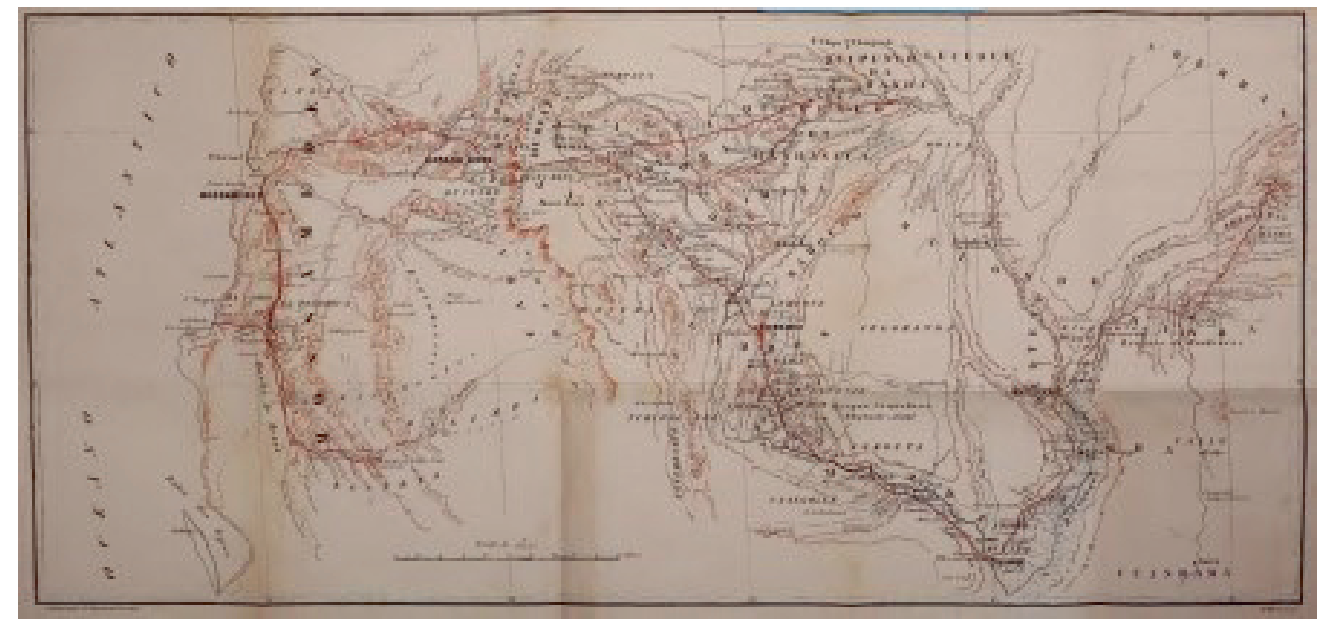

Figura 7.3 - Carta do sul de Angola. Fonte: In: CAPELO, Hermenegildo; IVENS, Roberto. De Angola à Contracosta: descrição de uma viagem pelo continente africano. Lisboa: Imprensa Nacional, 1886.

A carta acima mostra em detalhes a região que se estendia desde o centro urbano de Moçâmedes, no litoral, até os reinos do Humbe e Cuanhama, no interior. A intenção da carta foi apresentar a divisão e disposição dos principais grupos e os aspectos físicos do território, sobretudo no que se referia ao relevo e cursos d'água. Informações a esta carta de pequena escala depois seriam acrescidas por mapas militares de grande escala, que mostravam com maior precisão os detalhes do terreno, indicando as principais libatas e embalas (sedes e fortificações africanas), os pontos de água num território semiárido, os caminhos indígenas etc.

Durante os anos que sucederam a década de 1890 , vieram a somar os esfor- 
ços portugueses de exploração algumas expedições alemãs, haja vista a criação da colônia da África do Sudoeste Alemã em 1884. Entre 1899 e 1900, foi enviada ao sul de Angola uma expedição chefiada por Pieter van Kellen e Hugo Baum. Ela fora organizada sob os auspícios do Comitê Econômico Colonial em Berlim, em associação com a Companhia de Mossamedes (Paris) e a South West-Africa Company (Londres), e pretendia observar o valor econômico das regiões no sul de Angola.

Quando, enfim, toda a região do sul de Angola se tornou conhecida pelos europeus e, consequentemente, registrada em material cartográfico, teve início a tão discutida demarcação da fronteira entre Angola e o sudoeste africano (atual Namíbia). Naquele momento, em meio ao colonialismo europeu no território africano, Angola ficou definida como colônia portuguesa, enquanto o sudoeste africano se transformou em um protetorado alemão. Mas qual era a verdadeira fronteira entre as duas colônias?

O primeiro acordo firmado entre o governo português e o império alemão, conhecido por Convenção Luso-Alemã, de 30 de dezembro de 1886, definiu que a fronteira deveria se iniciar na foz do rio Cunene, estendendo-se até a região das cataratas da serra do Caná, e de lá seguiria o paralelo até o rio Cubango. Esse acordo feria o entendimento do governo português, que considerava o paralelo do Cabo Frio como a real fronteira entre as duas colônias, e não a foz do Rio Cunene, o que significava uma extensão de $111 \mathrm{~km}$ de diferença. Com a nova definição, parte da região da Ovambolândia, até então entendida integralmente como área de influência portuguesa, ficaria fora de seus domínios.

As cataratas da serra do Caná, que mais tarde passaram a figurar na documentação com o nome de Ruacaná, estão sempre presentes no debate acerca da fronteira. Na sequência, observa-se uma imagem, registrada na virada do século XIX para o século XX, da tão discutida catarata, um registro fotográfico feito pelo $1^{\circ}$ Tenente Filippe de Carvalho. 


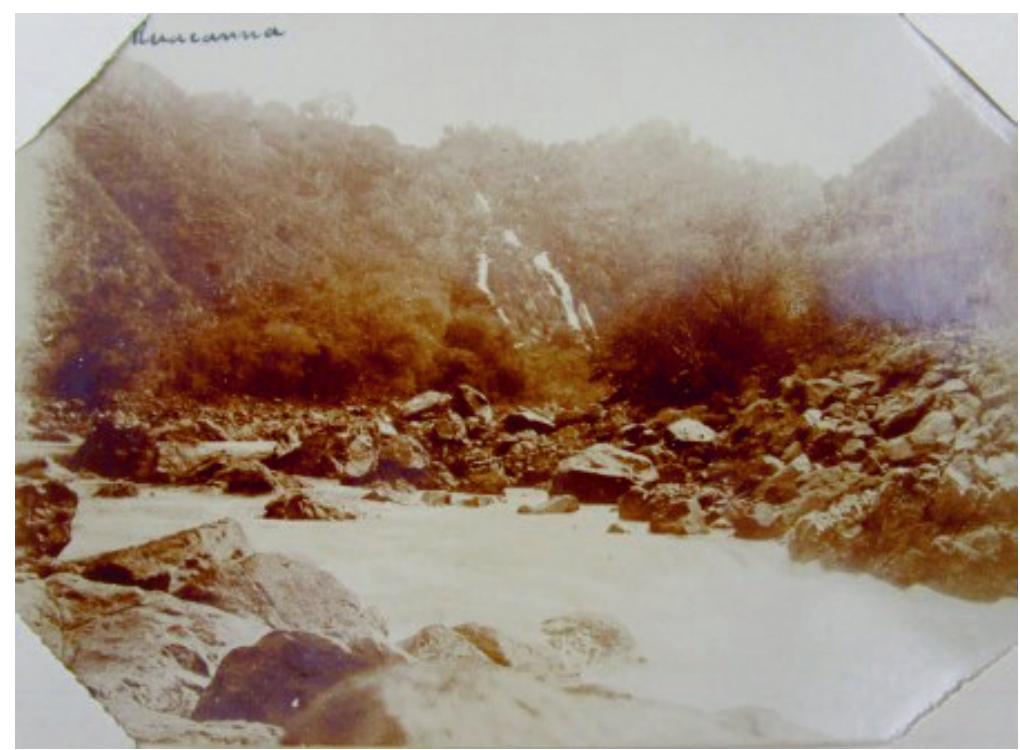

Figura 7.4 - Limites do Sul de Angola. Fronteira com a colónia alemã do sudoeste africano, 1895/1918. Fonte: Coła $3^{0}$ piso, Armário 9, Maço 21. Arquivo Histórico-Diplomático, Lisboa.

Embora contra a sua vontade, os representantes do governo português aceitaram os termos do acordo, porém os debates não cessaram. A questão se arrastou após a virada do século. A real localização da catarata no curso do Cunene, à qual a Convenção luso-alemã se referia, alimentou a discórdia. Enquanto o governo português alegava que a catarata em questão era a de Ruacaná, o império alemão defendia que a localização seria os rápidos de Nuangari, cerca de 200 kilometros acima da serra de Caná.

No mapa abaixo observamos os traçados correspondentes aos dois paralelos discutidos até então. O primeiro traçado se refere à posição alemã, enquanto o traçado inferior sinaliza a fronteira defendida pelo governo português. 


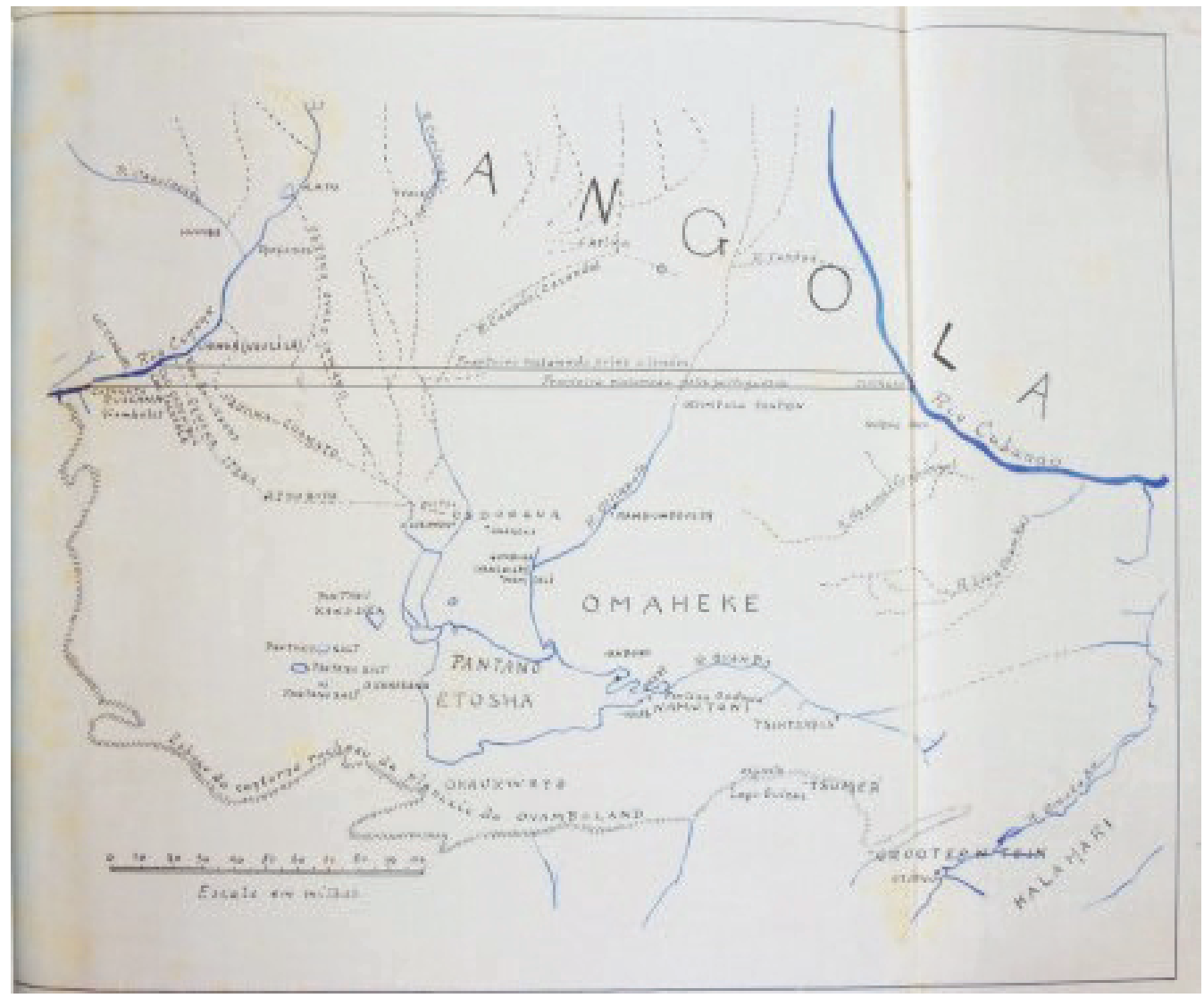

Figura 7.5 - Relatório de uma missão especial ao sul de Angola por Coronel Ernesto Machado. Fonte: Ministério das colônias. Direcção Geral das Colônias do Ocidente. Repartição de Angola e S. Tomé. Processo ñ 265-E. 1925. Arquivo Histórico Ultramarino em Lisboa.

O impasse acarretou na definição de um novo acordo em 1911. Nesse novo cenário, haveria uma faixa de onze quilômetros de largura, desde o Cuangar à Chimenha, entre o Cunene e o Cubango, na qual se adotaria um regime de neutralidade. O local ficava exatamente entre os dois pontos do Cunene discutidos por ambos os Estados. Tratava-se do nascimento da controversa zona neutra; assim, a partir daquele ano, haveria um espaço entre as duas colônias sobre o qual nenhum dos dois lados possuiria soberania.

No mapa a seguir, é possível ver a zona neutra cortando a Ovambolândia. 


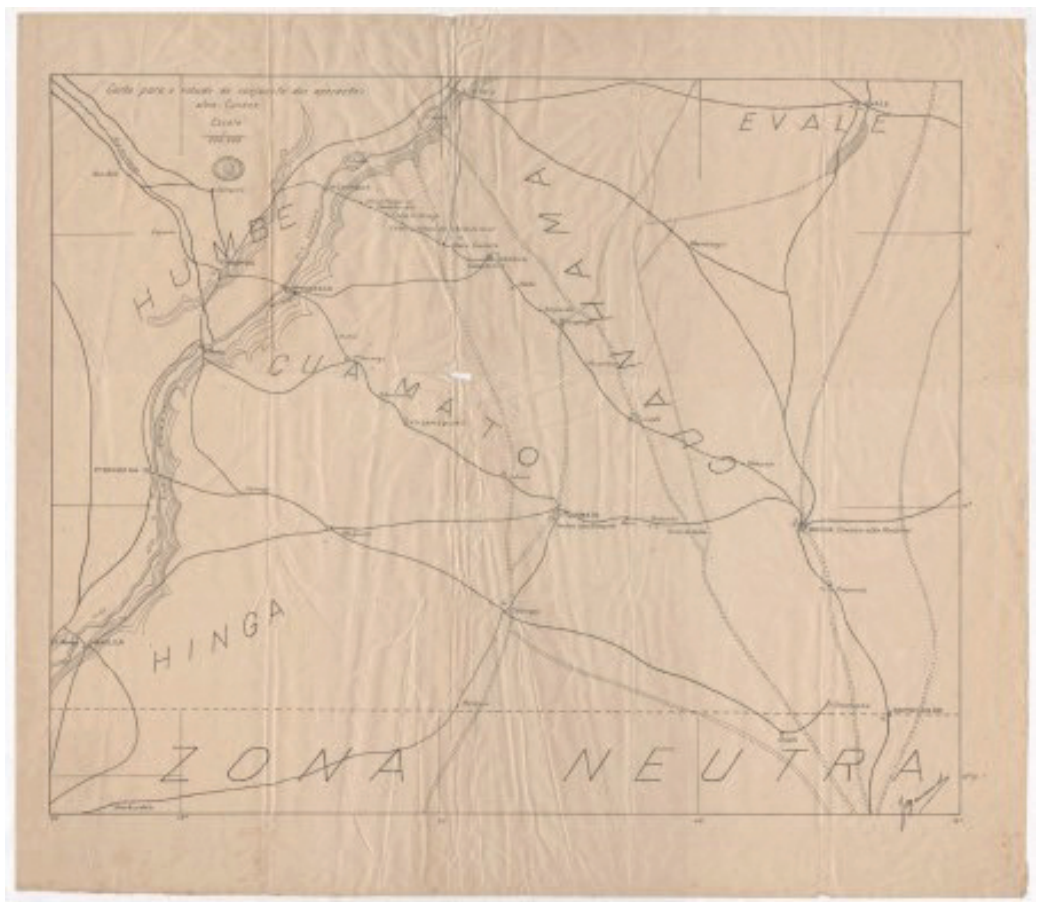

Figura 7.6 - Demarcação da Zona Neutra de Angola em território Ovambo. Fonte: Arquivo Histórico Ultramarino, Lisboa

A troca de soberania no território do sudoeste Africano após o fim da Primeira Guerra Mundial acirrou ainda mais as disputas, agora protagonizadas pelo governo português e os governos britânico e sul-africano (responsáveis pelo ex-protetorado alemão). Em 1920, uma missão portuguesa se encontrou com uma missão inglesa, representada por sul-africanos e chefiada pelo engenheiro hidrógrafo Mr. Kanthack, junto à catarata do Ruacaná. Os delegados dos dois países fronteiriços deram início aos trabalhos preliminares de demarcação de uma fronteira definitiva.

No entanto, definir uma fronteira não foi o único interesse de ambos os grupos. O lado sul da fronteira, marcado pelo deserto namibiano, era um empecilho natural para a fixação de europeus na região, que não se adaptavam à terra seca. Nesse cenário, as famosas cataratas do Ruacaná se mostravam como a solução para o problema, através de um audacioso projeto assinado pelo engenheiro alemão Schwarz. A ideia do engenheiro era desviar parte das águas do rio Cunene para o sul, a fim de provocar a inundação do lago Etocha, localizado em meio ao deserto do Kalahari, e assim alterar o sistema de cheias da região.

O projeto em questão não foi executado, porém os debates em torno da 
fronteira litigiosa tiveram fim em 1926, quando, na África do Sul, o governo português e o governo da União Sul Africana assinaram um acordo na Conferência do Cabo. O acordo em questão delimitou a fronteira em definitivo, dando-lhe a divisão política que perdura até hoje (conforme mapa a seguir). Além disso, criaram-se as leis que deveriam regulamentar os usos das águas do rio Cunene, com o propósito de sanar os problemas hidráulicos de ambos os lados da fronteira.

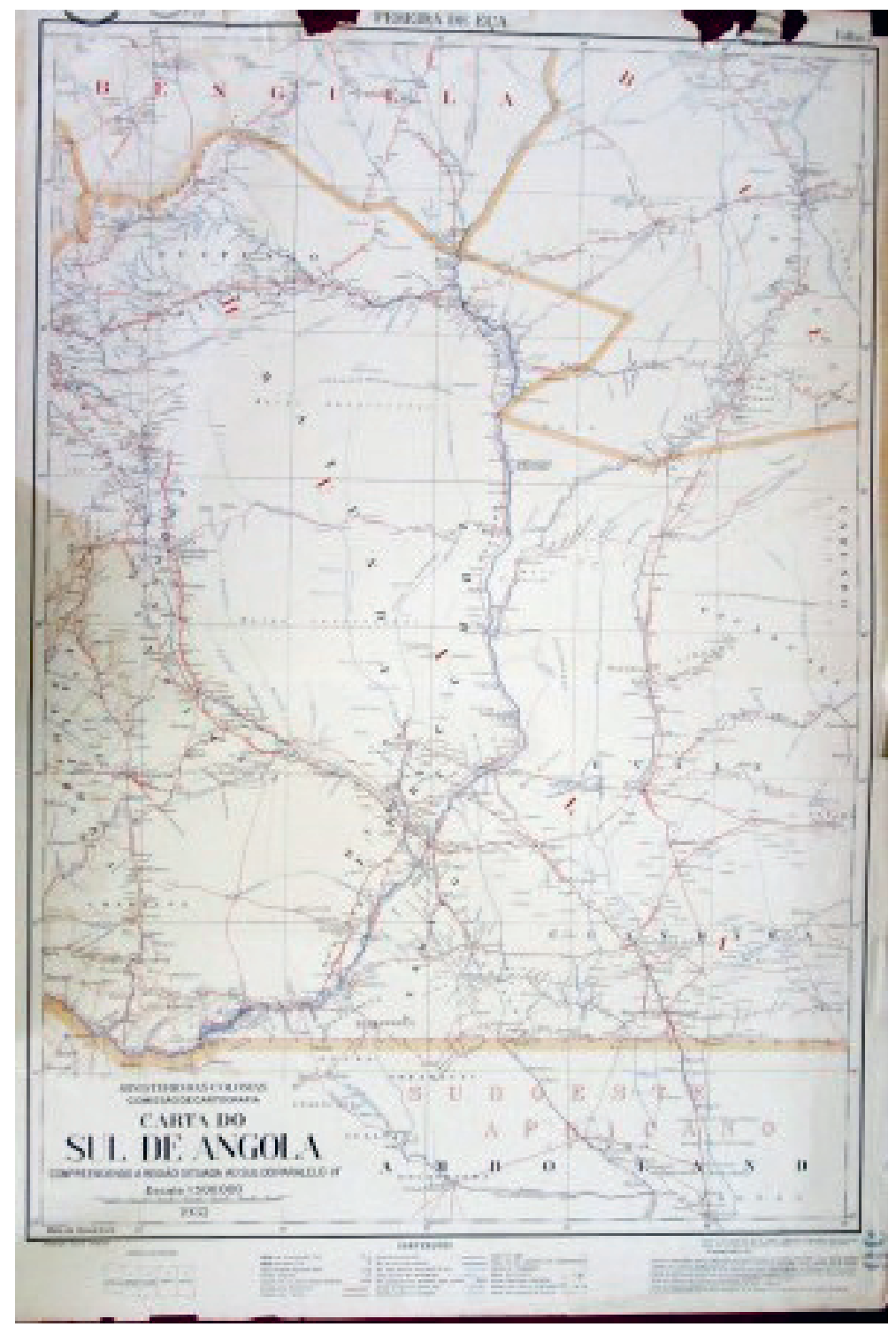

Figura 7.7 - Carta do Sul de Angola. Ministério das colônias. Comissão de Cartografia. Escala: 1:500.000, 1932. Fonte: Disponivel no Centro de Documentação e Informação do Instituto de Investigacãa Científica Tropical, Lisboa. 


\section{Referências}

CAPELO, H.; IVENS, R. De Angola à Contracosta: descrição de uma viagem pelo continente africano. Lisboa: Imprensa Nacional, 1886.

. De Benguella às terras de Iácca: Descrição de uma viagem na África Central e Ocidental. Lisboa: Imprensa Nacional, 1881.

CUNHA, D. L. Carta de 1725. In: Instruções políticas. Edição de Abílio Diniz Silva. Lisboa: Comissão Nacional para as Comemorações dos Descobrimentos Portugueses, 2001.

FURTADO, J. F. Oráculos da geografia iluminista: Dom Luís da Cunha e Jean Baptiste Bourguignon D'Anville na construção da cartografia do Brasil. Belo Horizonte: UFMG, 2012.

. Entre Angola e Moçambique: um projeto português de ligação terrestre entre as duas costas da África e suas fontes europeias e africanas: In: PAIVA, E. F.; SANTOS, V. S. (Org.). África e Brasil no mundo moderno. São Paulo: Annablume; Belo Horizonte: UFMG, 2012. p. 83-115.

HEINTZE, B. Exploradores alemães em Angola (1611-1954): apropriações etnográficas entre comércio de escravos, colonialismo e ciência. Frankfurt: Frobenius-Institut, 2010.

MÚRIAS, M. Travessia da África. Lisboa: Agência Geral das Colónias, 1936.

PÉLISSIER, R. História das campanhas de Angola. Lisboa: Editora Estampa, 2013. p. 66. v. 2.

VIEIRA, C. C. Os portugueses e a travessia do continente africano: projectos e viagens (1755-1814). 2006. Dissertação (Mestrado em História dos Descobrimentos e Expansão) - Universidade de Lisboa, Lisboa, 2006.

WESSELING, H. Dividir para Dominar: A partilha da África (1880-1914). Rio de Janeiro: Editora UFRJ: Editora Revan, 2008.

WHEELER, D.; PÉLISSIER, R. História de Angola. Lisboa: Edições Tinta da China, 2013. 